Journal of Applied Finance \& Banking, Vol. 11, No. 1, 2021, 61-71

ISSN: 1792-6580 (print version), 1792-6599(online)

https://doi.org/10.47260/jafb/1114

Scientific Press International Limited

\title{
Standard or Sustainable - Which Offers Better Performance for the Passive Investor?
}

\author{
Daniel C Khajenouri ${ }^{1}$ and Jacob H Schmidt ${ }^{2}$
}

\begin{abstract}
This research report studies the risk-adjusted performance of the major international equity indices against their ESG screened equivalents (MSCI World, MSCI USA, MSCI Emerging Markets, and MSCI Europe). The daily closing prices, returns, standard deviations, and Sharpe ratio characteristics are analyzed from 2013 to 2020. The current literature available from highly rated journals on the subject is also considered, which provided mixed results on the subject matter. We found no academic papers focusing specifically on analyzing the performance of indices and their ESG screened equivalents. With this paper, we intend to fill this gap in the current research available.

We conclude that for the passive investor, choosing ESG screened indices over the conventional equivalent has consistently provided better risk-adjusted returns over the long-term period. These findings are robust with the consistently higher Sharpe ratios over the eight-year period for each index. We predict ESG investments may continue to outperform due to changing retail and institutional investor preferences.
\end{abstract}

Keywords: Sustainable, Passive, Investment, ESG, Asset, Management, Wealth.

\footnotetext{
${ }^{1}$ Associate at the Chartered Institute for Securities \& Investment. University of St Andrews.

${ }^{2}$ Senior Lecturer \& Deputy Director of the Faculty Centre for Applied Finance and Banking at Regent's University London, CEO of Schmidt Research Partners Limited, and Chief Investment Analyst at NLPFM.
}

Article Info: Received: October 13, 2020. Revised: November 2, 2020.

Published online: November 5, 2020. 


\section{Introduction}

Sustainability has become a stronger and stronger theme in the asset management and wealth management industry. Global sustainable invested assets are valued at $\$ 30.7$ Trillion, with a 26\% annualized growth rate since 2012, with Europe being the largest sustainable investor and Japan with the fasted growing market (Global Sustainable Alliance, 2019). Evidently, this style of investment is predicted to continue to grow (Boston Consulting Group, 2019). This is especially true with the millennial and Generation $\mathrm{Z}$ generations entering the investment space where climate change is an important issue for them (Ernst \& Young, 2017).

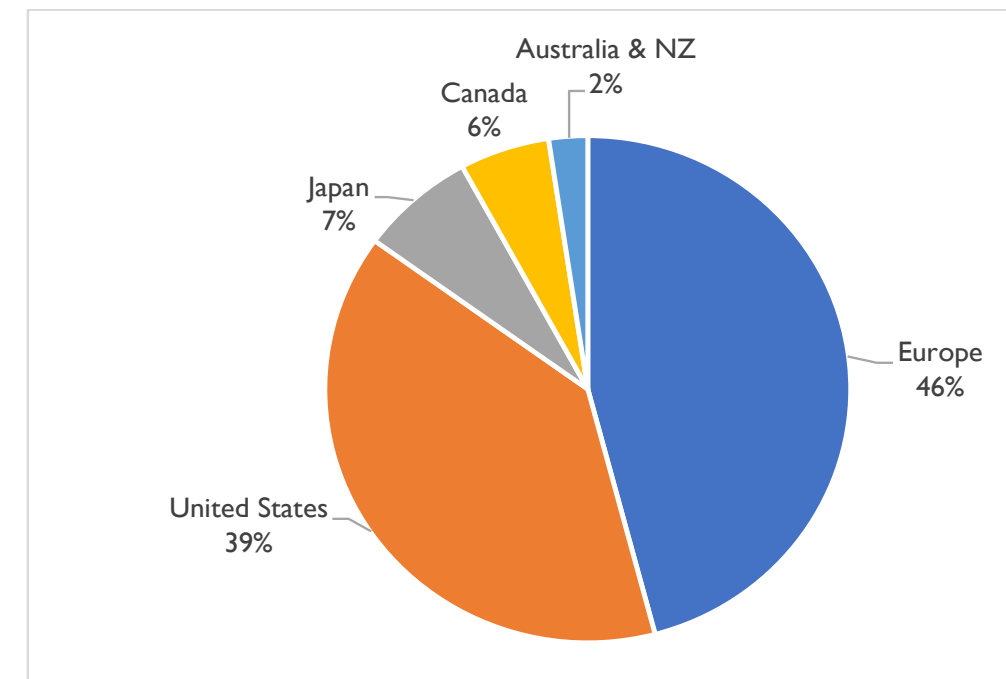

Figure 1: Geographic split of sustainable invested assets (Global Sustainable Investment Alliance, 2019)

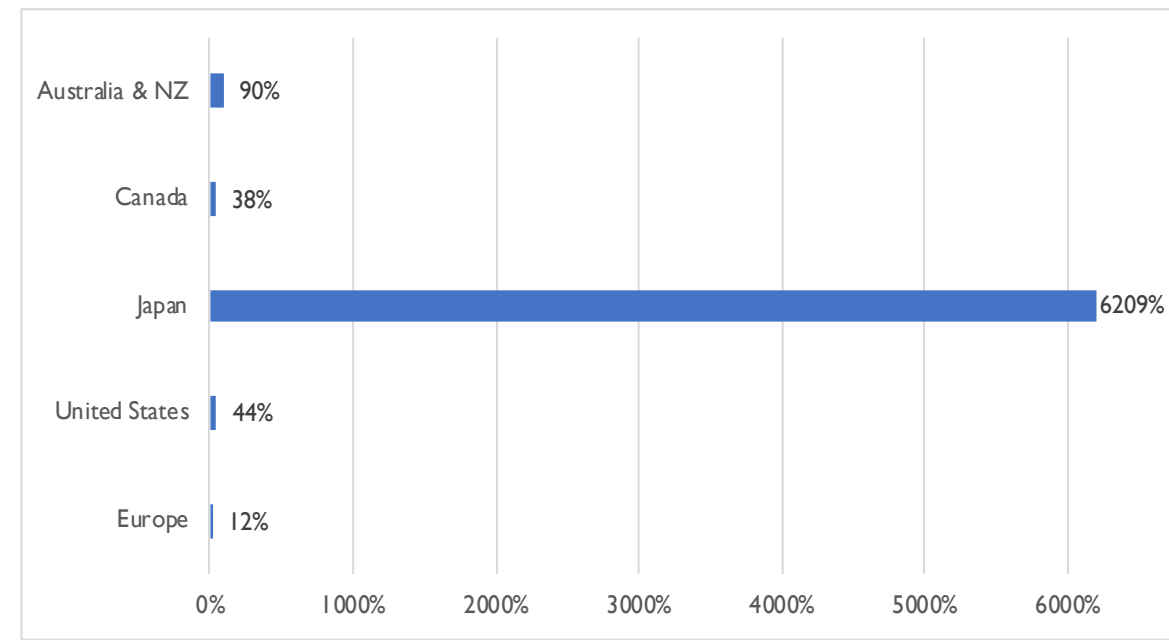

Figure 2: Annualized growth of sustainable invested assets by region 20122018 (Global Sustainable Investment Alliance, 2019) 
The large increase in Japan is due to pension funds incorporating a sustainable investment strategy.

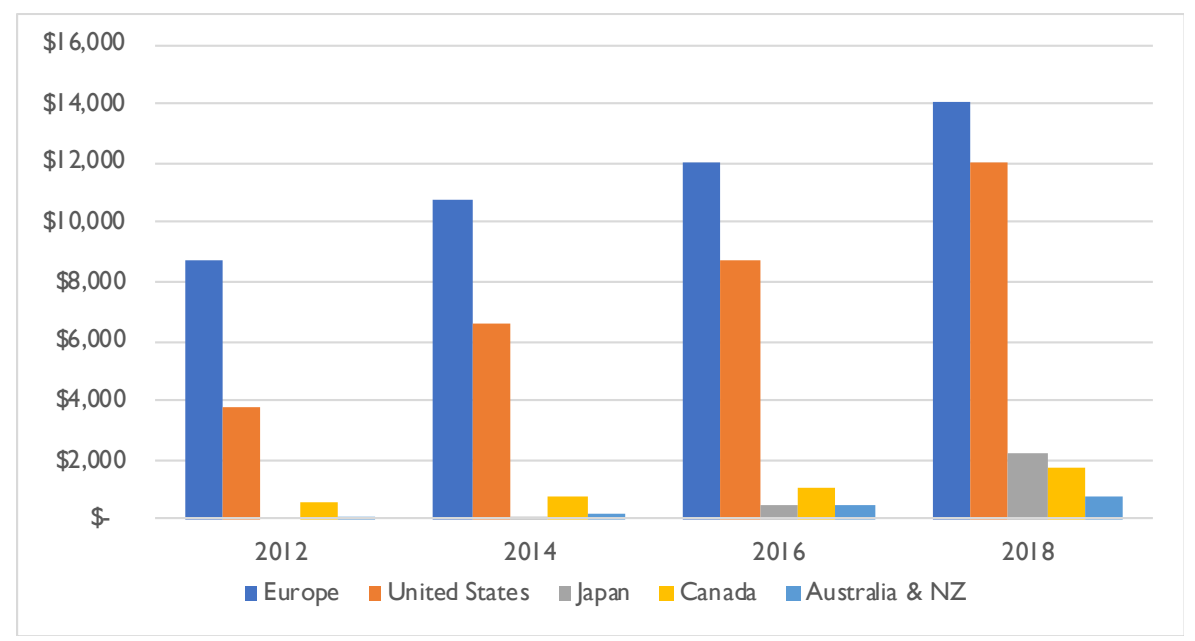

Figure 3: Geographic growth of sustainable invested assets (Global
Sustainable Investment Alliance, 2019)

Sustainable investment remains a loosely defined term within the industry. Some investors offer 'exclusionary screening', which removes investments which are defined as non-sustainable, for example, weapons and oil equities, this is the largest strategy by assets. Others may offer impact investments, designed to stimulate the underlying assets and create positive knock-on effects. For example, Vital Capital a private equity fund, invests in affordable housing, healthcare, water, agriculture, and renewable energy while delivering returns for their investors (Vital Capital, 2020). 'Sustainable themed investments' are the largest growing segment (193\% annualized), offering funds that contain 'sustainable' securities, such as renewable energy securities and green bonds (Pronina, 2019). See a summary of the growth of different strategies below. 


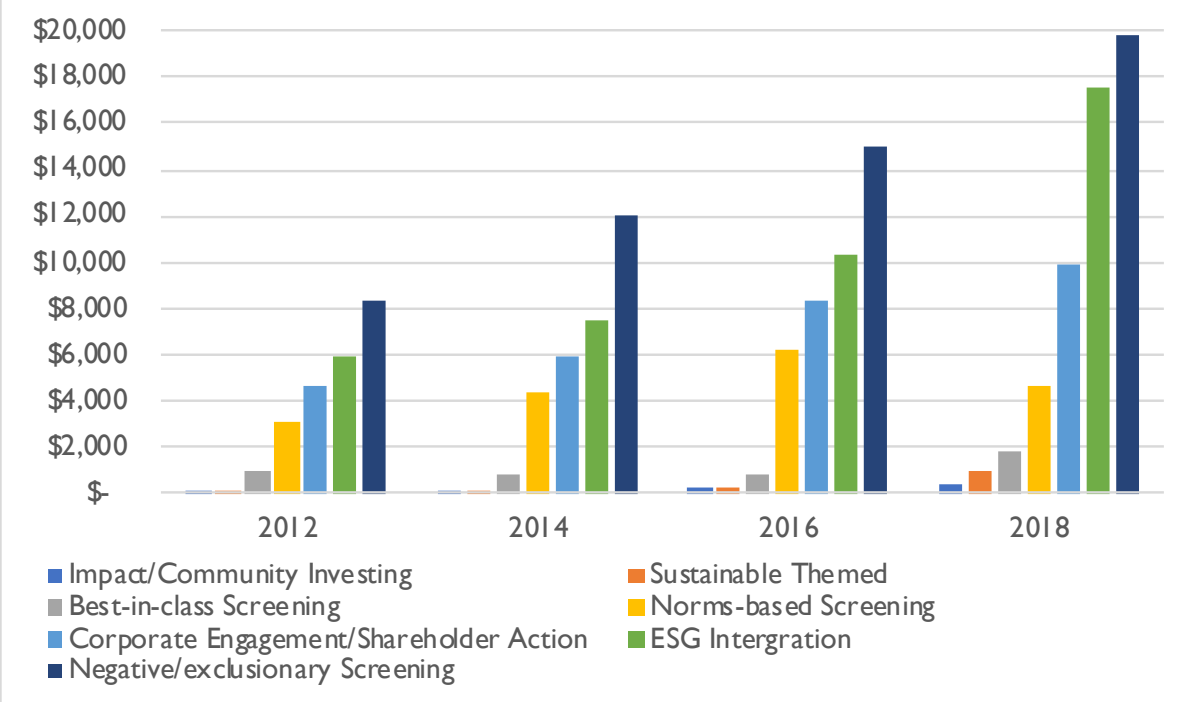

Figure 4: Growth of sustainable invested assets by strategy (Global Sustainable Investment Alliance, 2019)

As exclusionary investment is the largest strategy and is growing fast within the investment management and wealth management industry, we decided to measure the risk-adjusted returns of such investments against the standard indices which implement no such sustainable strategy. Sustainable strategies are predicted to become a larger part of investment management and wealth management, especially with the gen $\mathrm{z}$ and millennial generations entering wealth and financial markets, who believe particularly strong about sustainability (Ernst \& Young, 2017). We believe this research will be extremely relevant for both the financial academic and institutional communities.

Divestments from non-sustainable assets are also increasingly becoming a trend for investment managers, wealth managers, and retail investors alike. Blackrock, the largest investment manager in the world, with over $\$ 7$ trillion in assets under management, announced divestment from fossil fuel companies after social pressure (Pettifor, 2020). If divestments and growing disinterest in non-sustainable securities continue, future market valuations of such companies will be affected negatively (Active Sustainability, n.d.), further providing a case for sustainable investment. We expect changing preferences and continued divestments to drastically change the landscape of financial markets as time goes on.

This report is structured in several parts, firstly analyzing the current literature available on sustainable investment returns with identification of the research gap we intend to fill. Secondly, discussing the data selected and the research approaches chosen to reliably answer the research question. Thirdly, analyzing this data to compare the risk-adjusted performance over time and note any trends, and lastly, identifying and concluding our findings on whether an ESG screened passive investment strategy has performed better. 
This research design allows us to propose the following hypothesis:

$H O$ : ESG screened indices do not outperform their conventional equivalent.

HA: ESG screened indices outperform their conventional equivalent.

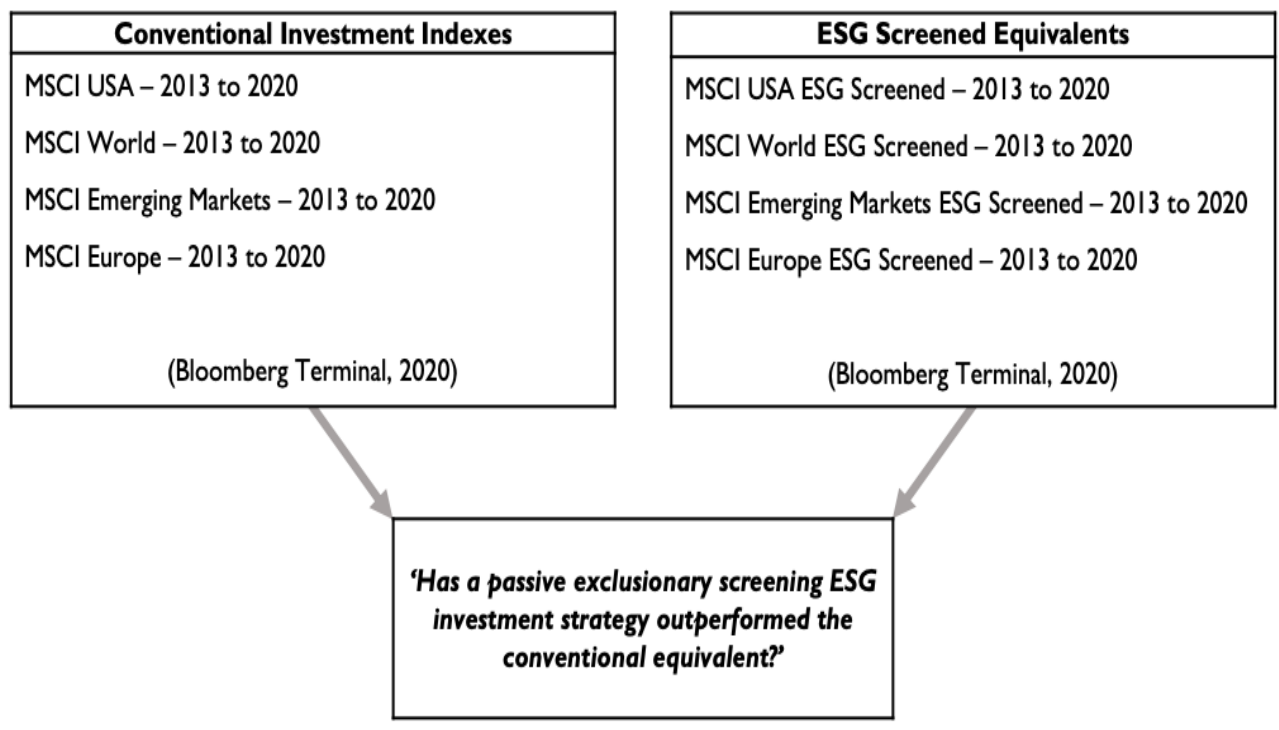

Figure 5: Conceptual research method

This subject has not been covered by the financial and environmental academic community. Our motivations for covering this topic is the lack of current and specific academic coverage on the topic and our own personal interest in sustainable investment and its relevant risk-adjusted returns.

\section{Literature Review}

A meta-analysis paper written by Gunnar Friede, Timo Busch \& Alexander Bassen in the Journal of Sustainable Finance \& Investment suggests that there is an empirical positive relationship between ESG and corporate financial performance. Roughly $90 \%$ of the studies suggested a positive relationship and the results also exhibit a stable long-term relationship between the two variables. The study looks into many regions, asset classes, non-portfolio, and portfolio related studies. The study combines primary and secondary data from around 2,200 individual studies (Friede, Busch and Bassen, 2015).

A paper written by Deutsche Bank investment researchers and an individual from Columbia University suggests that sustainable investment yields long-term performance for investors. This paper focuses on both passive investments and active managers. They found that ESG 'best in class' funds offer superior riskadjusted returns if 'well-executed'. Their meta-analysis looks into 56 academic papers, two literature reviews, and four meta-studies. They found exclusionary 
investing offers mixed to neutral results and non-exclusionary companies comparably have lower levels of cost of debt and equity. They found the market rewards companies for environmental consideration, followed closely by corporate factors (Fulton, Kahn and Sharples, 2012).

A study completed by Felipe Arias Fogliano de Souza Cunha and Carlos Patricio Samanez, which was published in the Journal of Business Ethics demonstrates that sustainable securities on the Brazilian Mercantile, Futures and Stock Exchange have mixed performance. Sustainable investments did not achieve satisfactory financial performance for the period of December 2005 to December 2010. The results found that sustainable investments had better liquidity and lower risk but fell short when returns, Sharpe ratios, Treynor ratios, Sortino ratios, and Omega were considered (Cunha and Samanez, 2013).

An analysis of the global performance of sustainable investments during the financial crisis was published in the Applied Financial Economics Journal. From 2004 to 2013, sustainable investments exhibited lower Sharpe ratios, and a relative decoupling of sustainable investing from markets during the crisis (Lean and Nguyen, 2014).

A study conducted on the popular sustainable indices was completed by Maria J. Charlo, Ismael Moya Ana, and M. Muñoz. The paper looked into the financial variables of firms that are considered to be socially responsible. The research concluded that socially responsible firms obtain higher profits margins while taking on the same level of systematic risk. They also exhibit greater sensitivity to the market, leverage levels, and company size (Charlo, Moya and Muñoz, 2015).

There are mixed results from the current literature available on the performance of sustainable investments over their conventional equivalents. This is due to a few reasons, however predominately because of the large amount and variety of securities that can be defined as a sustainable investment. Also, the loose definitions of 'sustainable', 'ESG', and 'socially responsible' companies damage the empirical validity of many of the studies.

The current literature available lacks research focusing on global exclusionary indices (which excludes companies associated with controversial, civilian and nuclear weapons and tobacco, that derive revenues from thermal coal and oil sands extraction, and that are not compliant with the United Nations Global Compact principles) and their conventional equivalents. We intend to fill this gap in the research with a focus on examining whether a passive investor would achieve improved risk-adjusted performance through sustainable exclusionary investment. 


\section{Data}

Because exclusionary investment funds are the most popular form of sustainable investment, we are focusing on the major exclusionary indices against the conventional equivalents. The following ESG screened indices replicate their conventional version but exclude all companies that are: Associated with controversial, civilian and nuclear weapons and tobacco, that derive revenues from thermal coal and oil sands extraction, and that are not compliant with the United Nations Global Compact principles. Other ESG compliant indices use different index construction methodologies, e.g. the MSCI ESG Leaders indices. These MSCI indices are non-investible, however, there are ETFs offered by Blackrock and Invesco which replicate them.

To answer the research question we used eight variables, focusing on the major global investment markets (Developed world, USA, emerging markets, and Europe): MSCI USA Total Return Index (Bloomberg Terminal, 2020), MSCI USA ESG Screened Total Return Index (Bloomberg Terminal, 2020), MSCI World Total Return Index (Bloomberg Terminal, 2020), MSCI World ESG Screened Total Return Index (Bloomberg Terminal, 2020), MSCI Emerging Markets Total Return Index (Bloomberg Terminal, 2020), MSCI Emerging Markets ESG Screened Total Return Index (Bloomberg Terminal, 2020), MSCI Europe Total Return Index (Bloomberg Terminal, 2020) and MSCI Europe ESG Screened Total Return Index (Bloomberg Terminal, 2020).

All securities are daily closing prices, priced in \$US dollars, and are from 01/01/2013 to $01 / 01 / 2020$.

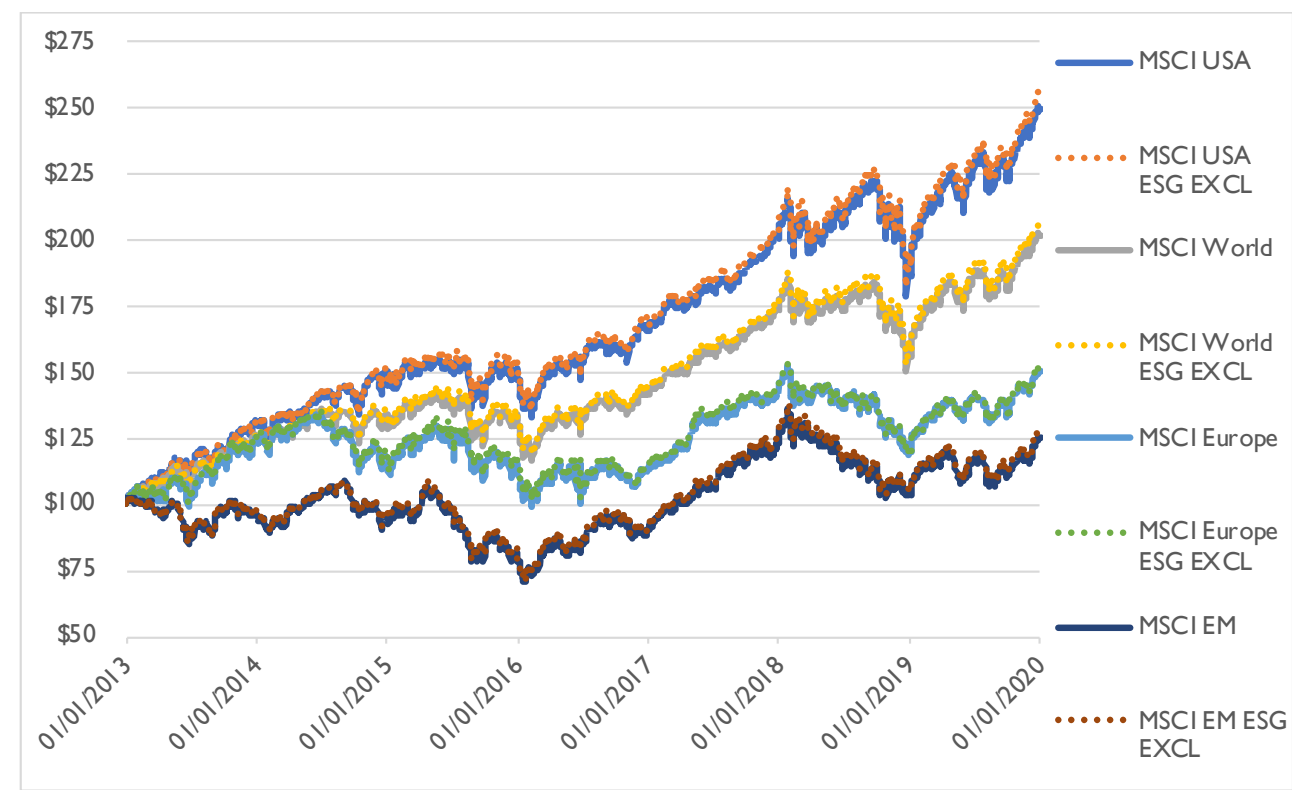

Figure 6: Rebased indices time-series (Bloomberg Terminal, 2020) 
The following table shows the daily percentage returns of the conventional and ESG screened indices. ESG time-series' broadly speaking exhibit higher momenta with skew and kurtosis. Using these statistics along with the Jarque-Bera test statistic and p-value, we can reject normality and estimate asymptotic distribution.

Table 1: Daily returns of index values

\begin{tabular}{|l|c|c|c|c|c|c|c|c|}
\hline & USA & $\begin{array}{c}\text { USA } \\
\text { ESG }\end{array}$ & World & $\begin{array}{c}\text { World } \\
\text { ESG }\end{array}$ & EM & $\begin{array}{c}\text { EM } \\
\text { ESG }\end{array}$ & Europe & $\begin{array}{c}\text { Europe } \\
\text { ESG }\end{array}$ \\
\hline Mean & $0.05 \%$ & $0.05 \%$ & $0.04 \%$ & $0.04 \%$ & $0.02 \%$ & $0.02 \%$ & $0.03 \%$ & $0.03 \%$ \\
\hline $\begin{array}{l}\text { Standard } \\
\text { Error }\end{array}$ & $0.02 \%$ & $0.02 \%$ & $0.02 \%$ & $0.02 \%$ & $0.02 \%$ & $0.02 \%$ & $0.02 \%$ & $0.02 \%$ \\
\hline $\begin{array}{l}\text { Standard } \\
\text { Deviation }\end{array}$ & $0.80 \%$ & $0.81 \%$ & $0.67 \%$ & $0.68 \%$ & $0.85 \%$ & $0.86 \%$ & $0.91 \%$ & $0.90 \%$ \\
\hline Kurtosis & 3.77 & 3.79 & 4.19 & 4.24 & 1.84 & 1.87 & 6.78 & 6.27 \\
\hline Skewness & -0.46 & -0.46 & -0.70 & -0.70 & -0.28 & -0.29 & -0.66 & -0.70 \\
\hline Range & $9.03 \%$ & $9.14 \%$ & $8.00 \%$ & $8.19 \%$ & $8.26 \%$ & $8.27 \%$ & $13.21 \%$ & $12.39 \%$ \\
\hline Minimum & $-4.05 \%$ & $-4.07 \%$ & $-4.90 \%$ & $-4.96 \%$ & $-4.98 \%$ & $-4.99 \%$ & $-8.77 \%$ & $-8.38 \%$ \\
\hline Maximum & $4.97 \%$ & $5.07 \%$ & $3.10 \%$ & $3.22 \%$ & $3.28 \%$ & $3.27 \%$ & $4.44 \%$ & $4.01 \%$ \\
\hline Count & 1,826 & 1,826 & 1,826 & 1,826 & 1,826 & 1,826 & 1,826 & 1,826 \\
\hline $\begin{array}{l}\text { Jarque-Bera } \\
\text { Test Statistic }\end{array}$ & 1,145 & 1,154 & 1,486 & 1,518 & 281 & 291 & 3,631 & 3,137 \\
\hline $\begin{array}{l}\text { Jarque-Bera } \\
\text { p-value }\end{array}$ & 0.00 & 0.00 & 0.00 & 0.00 & 0.00 & 0.00 & 0.00 & 0.00 \\
\hline
\end{tabular}

\section{Research Method}

A reliable research design was constructed with reputable sources and a variety of literature from highly rated academic journals to support our conclusions and provide context. Ethical consideration must always be considered in research, but as we are not conducting primary research and collecting from accurate and reputable secondary sources, serious ethical consideration is not necessary.

Each conventional index performance is measured against its ESG screened equivalent. The performance is observed on a year on year basis and total return basis over the seven-year period, any alpha is noted. To measure and compare risk, standard deviations of the indices are observed to measure any differences in volatility over the same periods. Lastly, to effectively measure the risk-adjusted performance of the securities, Sharpe ratios of the indices are calculated and compared. The \$US 3-month treasury bill of the time is used as the risk-free rate in all calculations.

This method provides strong quantitative conclusions on the historical performance of exclusionary sustainable investment performance. 


\section{Findings}

Our analysis shows that the ESG screened indices mostly have exhibited positive alpha over their conventional equivalents. See below for all alpha deriving from the sustainable indices versus their conventional equivalents. Green highlight represents ESG outperformance.

Table 2: Alpha of ESG screened indices over their conventional equivalents

(Bloomberg Terminal, 2020)

\begin{tabular}{|c|c|c|c|c|c|}
\hline & USA & World & Emerging & Europe & Total \\
\hline $\mathbf{2 0 1 9}$ & $0.41 \%$ & $0.48 \%$ & $0.63 \%$ & $-0.51 \%$ & $0.20 \%$ \\
\hline $\mathbf{2 0 1 8}$ & $0.35 \%$ & $0.11 \%$ & $-0.59 \%$ & $-0.11 \%$ & $-0.05 \%$ \\
\hline $\mathbf{2 0 1 7}$ & $-0.01 \%$ & $0.08 \%$ & $0.93 \%$ & $0.70 \%$ & $0.34 \%$ \\
\hline $\mathbf{2 0 1 6}$ & $-0.17 \%$ & $-0.49 \%$ & $-0.81 \%$ & $-2.06 \%$ & $-0.71 \%$ \\
\hline $\mathbf{2 0 1 5}$ & $0.80 \%$ & $0.79 \%$ & $0.44 \%$ & $1.07 \%$ & $0.62 \%$ \\
\hline $\mathbf{2 0 1 4}$ & $0.51 \%$ & $0.45 \%$ & $0.60 \%$ & $0.30 \%$ & $0.37 \%$ \\
\hline $\mathbf{2 0 1 3}$ & $0.62 \%$ & $0.90 \%$ & $1.02 \%$ & $1.29 \%$ & $0.77 \%$ \\
\hline Total Alpha & $5.61 \%$ & $4.17 \%$ & $2.47 \%$ & $0.57 \%$ & $2.56 \%$ \\
\hline
\end{tabular}

As seen above, every exclusionary index outperformed their conventional equivalent over the long-term period, reaching alpha as high as $5.61 \%$ in the USA. If one were to hold an equally weighted portfolio of the exclusionary indices, they would outperform the conventional equivalent every year apart from 2018 and 2016. Where every ESG screened index underperformed in 2016, is when President Trump unexpectedly won the US election, perhaps an interesting observation.

The data also statistically exhibits that the conventional indices have historically offered a lower risk investment through the measure of standard deviation. However, this doesn't necessarily mean that sustainable investments are riskier. This is because the exclusionary indices chosen in the research contain fewer holdings than their conventional equivalents and exclude entire industries. For example, MSCI USA has 636 constituents, while the MSCI USA ESG Screened index has 598 constituents, offering a lesser diversified investment (Bloomberg Terminal, 2020). Therefore, for measuring risk, this data lacks validity.

The second major result is the improved Sharpe ratio of ESG screened indices. The table shows annual Sharpe ratios along with the Sharpe ratio for the entire period. The green shaded areas show a higher relative Sharpe ratio. 
Table 3: Sharpe ratios of all indices (Using annualized standard deviations) (Bloomberg Terminal, 2020) (Sharpe, 1994)

\begin{tabular}{|c|c|c|c|c|c|c|c|c|}
\hline & USA & $\begin{array}{c}\text { USA } \\
\text { ESG }\end{array}$ & World & $\begin{array}{c}\text { World } \\
\text { ESG }\end{array}$ & EM & $\begin{array}{c}\text { EM } \\
\text { ESG }\end{array}$ & Europe & $\begin{array}{c}\text { Europe } \\
\text { ESG }\end{array}$ \\
\hline $\mathbf{2 0 1 9}$ & $2.39^{* *}$ & $2.36^{* *}$ & $2.60^{* *}$ & $2.60^{* *}$ & $1.48^{* *}$ & $1.53^{* *}$ & $1.94^{* *}$ & $1.88^{* *}$ \\
\hline $\mathbf{2 0 1 8}$ & -0.44 & -0.41 & -0.88 & -0.85 & -1.11 & -1.13 & -1.27 & -1.28 \\
\hline $\mathbf{2 0 1 7}$ & $3.00^{* *}$ & $2.89^{* *}$ & $3.66^{* *}$ & $3.60^{* *}$ & $3.87^{* *}$ & $3.95^{* *}$ & $2.58^{* *}$ & $2.79^{* *}$ \\
\hline $\mathbf{2 0 1 6}$ & $0.80^{* *}$ & $0.77^{* *}$ & $0.56^{* *}$ & $0.52^{* *}$ & $0.63^{* *}$ & $0.58^{* *}$ & -0.02 & -0.13 \\
\hline $\mathbf{2 0 1 5}$ & 0.03 & $0.08^{*}$ & -0.09 & -0.03 & -0.95 & -0.92 & -0.18 & -0.12 \\
\hline $\mathbf{2 0 1 4}$ & $1.13^{* *}$ & $1.16^{* *}$ & $0.55^{* *}$ & $0.60^{* *}$ & -0.20 & -0.15 & -0.51 & -0.49 \\
\hline $\mathbf{2 0 1 3}$ & $2.91^{* *}$ & $2.96^{* *}$ & $2.71^{* *}$ & $2.81^{* *}$ & -0.20 & -0.13 & $1.75^{* *}$ & $1.90^{* *}$ \\
\hline $\begin{array}{c}\text { Over } \\
\text { Period }\end{array}$ & $1.11^{* *}$ & $1.12^{* *}$ & $0.99^{* *}$ & $1.01^{* *}$ & $0.24^{* *}$ & $0.26^{* *}$ & $0.41^{* *}$ & $0.42^{* *}$ \\
\hline
\end{tabular}

As seen above, regardless of the more volatile exclusionary indices, they consistently exhibit a higher Sharpe ratio. This reinforces hypothesis HA that passive sustainable investments have consistently outperformed the conventional equivalents. Most Sharpe ratios exhibit a t-test significance at the $1 \%$ level. For statistical significance, we believe a simple t-test is sufficient for the Sharpe ratios.

\section{Final Remarks}

The results confirm our hypothesis that exclusionary sustainable investment indices perform better than the conventional equivalents for the passive investor.

We conclude that the volatility results lack validity due to the exclusionary indices having fewer constituents and offering fewer industries, the ESG screened indices are a less diversified index and therefore inherently carries more risk. Both the returns of the ESG screened indices and the Sharpe ratios outperform the standard indices over the long-term. We believe this paper can have implications on the future investment strategies of the investment management and wealth management industries.

We can expect this trend of ESG screened investment outperformance to continue due to two reasons:

- Continued divestments from retail and institutional investors.

- The next generation of investors (millennials and Generation Z) interest in sustainable investments and their subsequent rise of influence in financial markets directly, and indirectly through the investment management and wealth management industries.

Future research will focus on other ESG investment strategies. 


\section{References}

[1] Activesustainability.com. (n.d.). Sustainable investment and divestment.

[2] Bloomberg LLP. (2020). Bloomberg Terminal.

[3] Boston Consulting Group. (2019). How Sustainable Finance Is Shifting the Future of Investing.

[4] Charlo, M., Moya, I. and Muñoz, A. (2015). Sustainable development and corporate financial performance: a study based on the FTSE4Good IBEX Index. Business Strategy and the Environment, 24(4), pp. 277 - 288.

[5] Cunha, F. and Samanez, C. (2013). Performance Analysis of Sustainable Investments in the Brazilian Stock Market: A Study About the Corporate Sustainability Index (ISE). Journal of Business Ethics, 117(1), pp. 19 - 36.

[6] Ernst \& Young. (2017). Sustainable Investing: The Millennial Investor.

[7] Friede, G., Busch, T. and Bassen, A. (2015). ESG and Financial Performance: Aggregated Evidence from more than 2000 Empirical Studies. Journal of Sustainable Finance \& Investment, 5(4), pp. 210 - 233.

[8] Fulton, M., Kahn, B. and Sharples, C. (2012). Sustainable Investing: Establishing Long-Term Value and Performance. Deutsche Bank Group.

[9] Global Sustainable Alliance. (2019). 2018 Global Sustainable Investment Review. Global Sustainable Alliance.

[10] Lean, H. and Nguyen, D. (2014). Policy uncertainty and performance characteristics of sustainable investments across regions around the global financial crisis. Applied Financial Economics, 24(21), pp. 1367 - 1373.

[11] Pettifor, A. (2020). BlackRock gets praise for coal divestment. What it really needs is regulation. The Guardian.

[12] Pronina, L. (2019). What Are Green Bonds and How 'Green' Is Green?. Bloomberg LLP.

[13] Sharpe, W. (1994). The Sharpe Ratio. Journal of Portfolio Management, 21(1), pp. 49-58.

[14] Vital Capital. (2020). Vital - Investing for meaningful outcomes and strong returns. 